Retrospective Study

\title{
Percutaneous Vertebroplasty for Symptomatic Schmorl's Nodes: 11 Cases with Long-term Follow-up and a Literature Review
}

Shi-Cheng He, MD, Bin-Yan Zhong, MD, Hai-Dong Zhu, MD, Wen Fang, MD, Li Chen, MD، Jin-He Guo, MD, Gang Deng, MD, and Gao-Jun Teng, MD, PhD

From: Department of Radiology, Zhongda Hospital, Medical School, Southeast University, Nanjing, China

Address Correspondence: Gao-Jun Teng, MD, PhD Department of Radiology, Zhong-da Hospital, Medical School, Southeast University, 87 Dingjiaqiao Rd, Nanjing 210009, China E-mail: gjteng@vip.sina.com

Disclaimer: Shi-Cheng $\mathrm{He}$, Bin-Yan Zhong, and Hai-Dong Zhu contributed equally to this project. There was no external

funding in the preparation of this manuscript.

Conflict of interest: Each author certifies that he or she, or a member of his or her immediate family, has no commercial association (i.e., consultancies, stock ownership, equity interest, patent/licensing arrangements, etc.) that might pose a conflict of interest in connection with the submitted manuscript.

Manuscript received: 11-17-2015 Revised manuscript received: o6-02-2016 Accepted for publication: 07-27-2016

Free full manuscript: www.painphysicianjournal.com
Background: Percutaneous vertebroplasty (PVP) is commonly used to treat symptomatic vertebral compression fractures. However, its long-term effectiveness and safety for use in the treatment of symptomatic Schmorl's nodes (SNs) refractory to conservative treatment is uncertain.

Objectives: To present a case series with PVP for symptomatic SNs not responding to conservative therapy and assess the effectiveness and safety for such treatment with long-term follow-up. To present a review of the literature regarding SNs and treatment options.

Study Design: Single center retrospective observational study.

Setting: This study consists of patients from a large academic center in China.

Methods: Between January 2008 and December 2013, 11 patients suffering from symptomatic SNs that were refractory to medical or physical therapy, underwent PVP procedures in our department. All patients had a definitive diagnosis of SNs by magnetic resonance imaging (MRI) and computed tomography (CT). The visual analog scale (VAS) was assessed preoperatively at 4 hours, at one month, and every 6 months postoperatively during the long-term (mean: 58.0 months) follow-up period.

Results: Each of the 11 patients reported an immediate and distinct relief of their back pain. No one reported a worsening of symptoms. The VAS decreased from an average preprocedural score of 7.9 to a postprocedural score of 2.1 at 4 hours. The VAS averaged 1.8 during the mean followup period of 58.0 (range 24.1 to 98.9) months. There were no postoperative complications during the follow-up period. At the end of the follow-up period, all 11 patients were unrestricted in their activities.

Limitations: This study is a retrospective study with a small sample size.

Conclusions: PVP is an effective and safe procedure for the treatment of symptomatic SNs, which are refractory to medical or physical therapy.

Key words: Percutaneous vertebroplasty, symptomatic Schmorl's nodes, vertebral endplate fracture, endplate osteonecrosis, Modic changes

Pain Physician 2017; 20:69-75 n 1927, Christian Georg Schmorl first described a specific type of vertebral lesion which became known as a Schmorl's node (SN) (1). SNs are herniation of the nucleus pulposus (NP) through the cartilaginous and bony endplate into the adjacent vertebral body (2). The reported prevalence of SNs ranges from $38 \%$ to as high as $79 \%$ in cadaver studies $(3,4)$. SNs are often asymptomatic, incidental findings on magnetic resonance images (MRI) (5). However, SNs can be symptomatic, becoming a source of chronic low back pain (6). If the $\mathrm{SN}$ is painful, symptoms may resolve spontaneously, or may respond to medical and 
physical management (5). Percutaneous vertebroplasty (PVP), a minimally invasive surgery, has been reported to be an effective treatment for symptomatic SNs not responding to conservative therapy $(7,8)$. Nevertheless, the long-term effectiveness and safety of PVP in treatment of symptomatic SNs has been unclear thus far.

In this report, we present a case series of patients who underwent PVP procedures for the treatment of symptomatic SNs and assess the effectiveness and safety of PVP over a long-term follow-up period. In addition, we review the literature regarding SNs and their treatment options.

\section{Methods}

This retrospective study was approved by the ethical review committee of our institution. From January 2007 to December 2013, 819 patients underwent PVP procedures in our department for the treatment of back pain that did not respond to medical management and physical therapy. Among these 819 patients, 11 patients were diagnosed with symptomatic SNs via computed tomography (CT) scans and MRI. A CT scan was performed to identify the main cause of pain. An MRI examination was performed to determine whether the back pain was the result of symptomatic SNs or other vertebral body abnormalities. The 11 patients all presented with back pain of at least 6 weeks duration that was refractory to conservative therapy, including analgesics, bed rest, bracing, and physical therapy.

\section{PVP Procedure}

All PVP procedures were performed under local anesthesia using $2 \%$ lidocaine. The procedure was performed using a unilateral transpedicle approach with a Murphy set (Cook, Inc., Bloomington, Indiana, USA) under fluoroscopic guidance with a C-arm angiographic unit (Innova 3100, GE Healthcare System or FD 20, Philips Medical) by interventional radiologists (Gao-Jun Teng or Shi-Cheng He). The volume of cement [a mixture containing $70 \%$ polymethylmethacrylate (PMMA) (Corinplast TM3, Corinlnc, Gloucestershire, United Kingdom) and $30 \%$ sterilized barium powder (Dongfeng Chemical Inc., Qingdao, China)] varied according to the $\mathrm{SN}$ location $(3-5 \mathrm{~mL}$ per thoracic vertebrae and 4-6 mL per lumbar vertebrae). As long as the patient could tolerate the operation, multiple vertebral levels were treated during a single session. A CT scan was performed on all patients within 3 days after the operation to observe the distribution of the PMMA.

\section{Data Collection}

The visual analog scale (VAS) was administered to all 11 patients preoperatively and postoperatively at 4 hours, one month, and then every 6 months during the follow-up period. After the PVP procedure, all of the patients underwent $C T$ and MRI examinations at one and 6 months and then every 6 months thereafter. The patients were instructed to return to our hospital for an evaluation if they developed any new symptoms or injuries, such as a new vertebral fracture, the recurrence of back pain, or any spinal cord compression symptoms that might be related to the procedure. The final follow-up date was September 1, 2015. All statistical analyses were performed using the PASW Statistics software (Version 18.0, IBM Corporation, Somers, NY, USA).

\section{Results}

Five men and 6 women with a mean age of 65.3 years (range 36 to 87 ) were included in this study. The detailed information about the 11 patients is shown in Table 1. All 11 patients were diagnosed via CT and MRI. Preoperatively, the back pain was confirmed to result from symptomatic SNs. The procedures were performed successfully under the guidance of a C-arm angiographic unit in all patients. No complications, such as cement leakage, pulmonary embolism, spinal cord injury, or nerve root injury, were observed. All patients reported obvious improvement in their back pain 4 hours after the procedure. The average VAS score decreased from 7.9, preoperation to 2.1, 4 hours post PVP. During the mean time of 58.0 months' (range 24.1 to 98.9 months) follow-up, the patients' VAS average remained at approximately 1.8 , and no complications, including new vertebral fractures, recurrence of back pain, or spinal cord compression symptoms, were observed. All 11 patients had unrestricted activity at the end of the followup period.

\section{Case Presentation}

A 36-year-old man was referred to our department due to low back pain for 6 months. He had injured his waist 5 years ago and was treated with conservative measures (without a detailed hospital examination). He gradually recovered from the back pain. Six months prior to our examination, the patient's back pain recurred and became progressively worse. He was diagnosed with acute SNs at L4-5 via MRI and CT (Fig. 1). He underwent rami communicans nerve block but experienced little benefit. We successfully performed a PVP with a 
Table 1. Clinical data.

\begin{tabular}{|l|c|c|c|c|c|c|c|c|c|c|c||}
\hline Case & Gender & Age & Location & $\begin{array}{c}\text { Operation } \\
\text { time }\end{array}$ & $\begin{array}{c}\text { VAS } \\
\text { Preoperation }\end{array}$ & $\begin{array}{c}\text { VAS } \\
\text { hours } \\
\text { after }\end{array}$ & $\begin{array}{c}\text { VAS } \\
\text { One } \\
\text { month } \\
\text { after }\end{array}$ & $\begin{array}{c}\text { VAS } \\
\text { 6 month } \\
\text { after }\end{array}$ & $\begin{array}{c}\text { VAS } \\
\text { I2 } \\
\text { month } \\
\text { after }\end{array}$ & $\begin{array}{c}\text { VAS } \\
\text { last } \\
\text { follow- } \\
\text { up }\end{array}$ & $\begin{array}{c}\text { Follow-up } \\
\text { (months) }\end{array}$ \\
\hline 1 & M & 36 & L4/L5 & $2011-02-11$ & 9 & 1 & 1 & 1 & 1 & 1 & 55.4 \\
\hline 2 & F & 58 & T12 & $2009-02-18$ & 7 & 2 & 2 & 2 & 2 & 2 & 79.5 \\
\hline 3 & F & 65 & T11/T12 & $2011-07-22$ & 8 & 3 & 3 & 3 & 3 & 3 & 50.1 \\
\hline 4 & M & 87 & L2 & $2012-01-30$ & 8 & 2 & 1 & 1 & 1 & 1 & 43.7 \\
\hline 5 & F & 60 & L1 & $2007-07-17$ & 8 & 4 & 4 & 4 & 4 & 4 & 98.9 \\
\hline 6 & F & 86 & L2/L3 & $2010-04-13$ & 7 & 3 & 3 & 3 & 3 & 3 & 65.6 \\
\hline 7 & F & 65 & T10/T12/L1 & $2010-04-15$ & 8 & 1 & 0 & 0 & 0 & 0 & 65.5 \\
\hline 8 & M & 78 & L3 & $2010-09-23$ & 8 & 2 & 2 & 2 & 2 & 2 & 60.1 \\
\hline 9 & F & 70 & T9 & $2010-12-02$ & 8 & 1 & 0 & 0 & 0 & 0 & 57.8 \\
\hline 10 & M & 51 & T12 & $2013-09-09$ & 8 & 3 & 3 & 3 & 3 & 3 & 24.1 \\
\hline 11 & M & 62 & T12 & $2012-08-24$ & 8 & 1 & 1 & 1 & 1 & 1 & 36.8 \\
\hline
\end{tabular}

VAS = visual analog scale, $\mathrm{M}=$ male, $\mathrm{F}=$ female

unilateral puncture. The volume of the injected PMMA was $5 \mathrm{~mL}$ at L4 and $4 \mathrm{~mL}$ in L5. No cement leaks occurred within the intervertebral discs (Figs. 2 - 3). The VAS of the patient was 9 preoperation and improved to 3 when he was reassessed 4 hours after the PVP. The improvement in the pain was sustained, and he experienced no complications during the $\mathbf{5 5 . 4}$ months of follow-up. At the last follow-up evaluation, the patient was satisfied with the procedure results and was able to perform all normal daily activities.

\section{Discussion}

SNs were first described in 1927 by Christian Georg Schmorl as a herniation of the nucleus pulposus through the cartilaginous and bony endplate into the body of the adjacent vertebra $(1,2)$. Until now, the pathophysiology of SNs was still uncertain and under debate. Abnormalities of the vertebral blood vessels during development is the most convincing and classical theory $(9,10)$. The persistence of abnormal vascular channels could weaken the endplate and allow the nucleus pulposus to herniate into the vertebra (9). SNs are common in normal individuals and are often asymptomatic, incidental findings via MRI (5). However, prior epidemiological studies have revealed that patients with SNs may have a higher incidence of low back pain compared to the normal population (11). Symptomatic SNs can lead to axial back pain or even cause significant radicular pain if the node extravasates into the spinal canal and neural foramen (12). Moreover, Hansson et al (13) suggested that SNs may represent an early stage of endplate fracture.
The symptoms associated with some SNs may be due to inflammatory changes around the herniated nucleus pulposus of the diseased vertebra (14). Hamanishi et al (15) evaluated the lumbar spine MRI examinations of 400 patients with low back pain and a control group of 106 patients. The presence of SNs was more frequent in the symptomatic group (19\%) compared to the asymptomatic group (9\%). Williams et al (16) demonstrated on MRI that vertebral body marrow changes adjacent to symptomatic SNs, were T1 dark and $\mathrm{T} 2$ bright. This finding is most consistent with edematous/inflammatory marrow changes adjacent to symptomatic SNs. Thus, an MRI is the gold standard imaging technique to detect symptomatic SNs (6). In our study, each patient was diagnosed with an acute SN via MRI.

Several therapeutic options are available to treat symptomatic SNs, such as PVP, fusion, and conservative treatment. Previous prospective randomized trials have already proven that PVP is a useful and effective approach to treat vertebral compression fractures $(17,18)$. In our literature review (using PubMed search in October 2015), only one clinical study and one case report focused on the effectiveness of PVP for the treatment of back pain associated with a symptomatic vertebral body SN $(7,8)$. Masala et al $(7)$ conducted a clinical study that included 23 patients. The patients were treated with PVP for symptomatic SNs that were unresponsive to medical management and physical therapy. In this study, 18 patients reported improved back pain 4 hours after PVP, and 5 patients reported unchanged back 


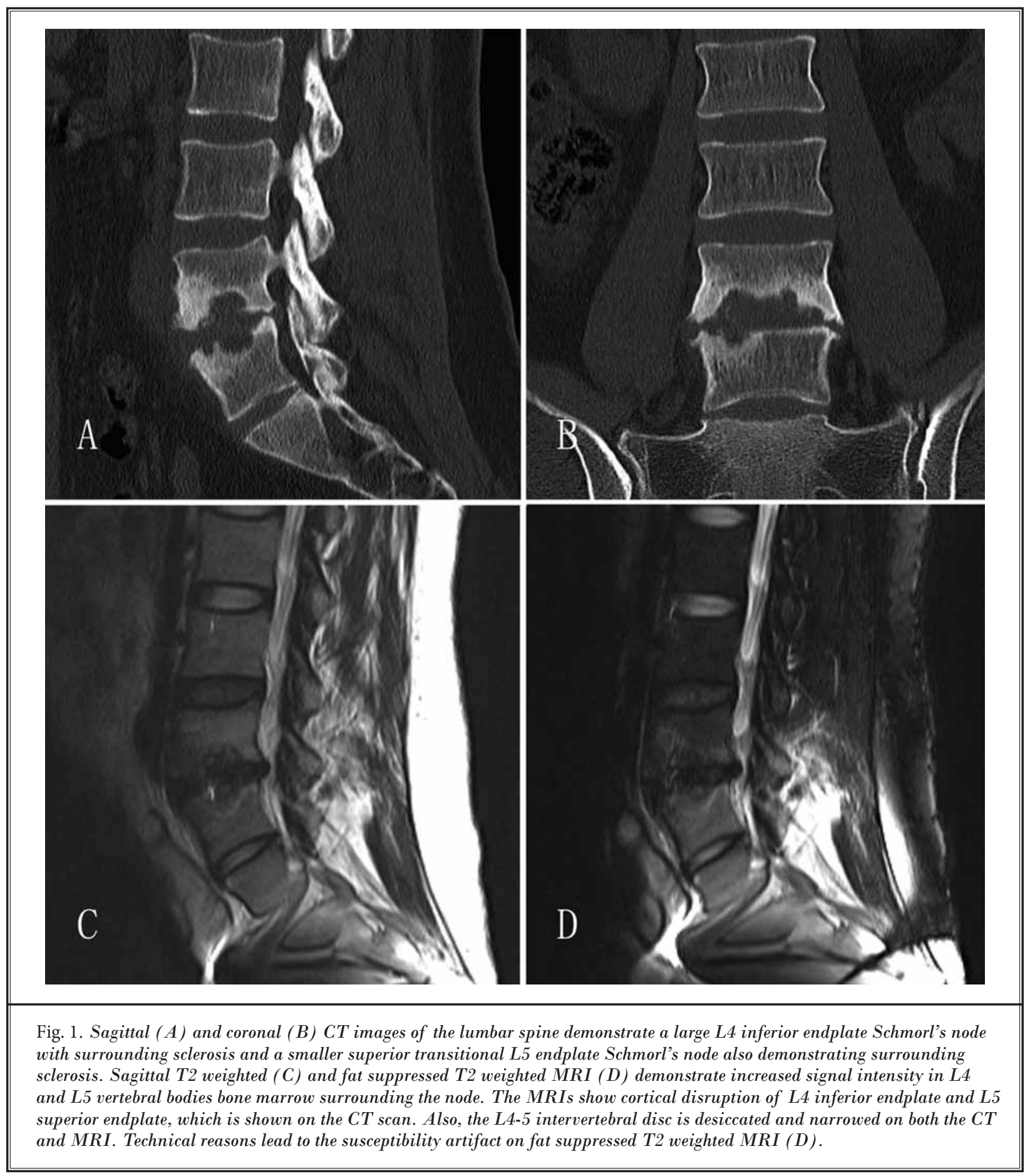

pain. No patient reported a worsening of symptoms. The VAS score decreased from 8.4 to 2.3. However, this study was limited in that the follow-up period was not clearly defined, and the investigators did not report the long-term outcomes after the PVP procedure. In addition, the long-term complications related to the procedure were not reported. In our study, the patients completed a long-term follow-up with a mean time of 58.0 


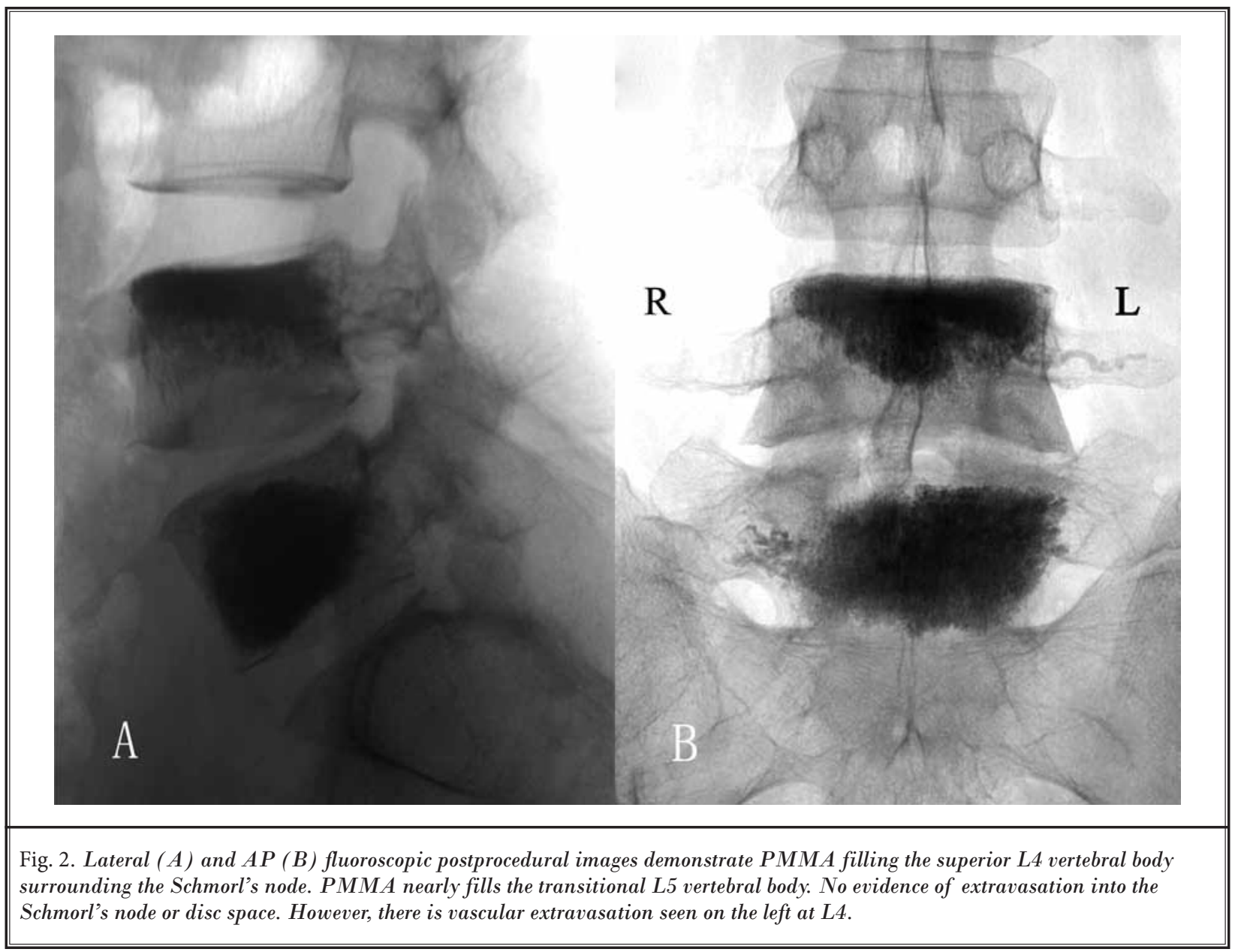

months. We determined that PVP can achieve sustained pain reduction for patients with symptomatic SNs, and we observed no complications during the follow-up.

The injected PMMA distributed either within the edematous rim of marrow adjacent to the Schmorl's node or near completely filled the vertebral body (19). There was no cement leakage into the disc. Masala et al (7) hypothesized that the lack of disc leakage may be due to increased pressure from the herniated disc or due to the presence of marginal peridiscal bone sclerosis caused by adjacent boney trabecular impaction occurring with the intravertebral body disc herniation.

Additionally, there are a few other methods of treatment for symptomatic SNs. Fusion was first reported by Peng et al (20) to be efficacious in alleviating severe lower back pain due to SNs. Clinicians recommended that patients with SNs and chronic low back pain, especially young patients who present with MRI findings suggestive of advanced disc degeneration, should undergo fusion of the involved segment (21). However, compared to PVP, fusion surgery inflicts more trauma, and the patient requires a longer recovery period. Additionally, the patient will incur a higher treatment cost. Other methods, such as a rami communicans nerve block, medical treatment, and physical therapy, can also reduce the back pain caused by symptomatic SNs $(22,23)$. We strongly suggest PVP to reduce pain if the patient does not respond to other treatments, as illustrated in the case presentation.

This study has some limitations. First, this study was performed retrospectively which has less creditability than a prospective study. Additional prospective studies are needed to assess the effectiveness and safety of the PVP procedure. Second, there were only 11 patients in this study. Study results based on a small sample size may not be convincing. Third, only patients who underwent PVP were included in our study; no control or alternative treatment, such as fusion, groups were assessed. 


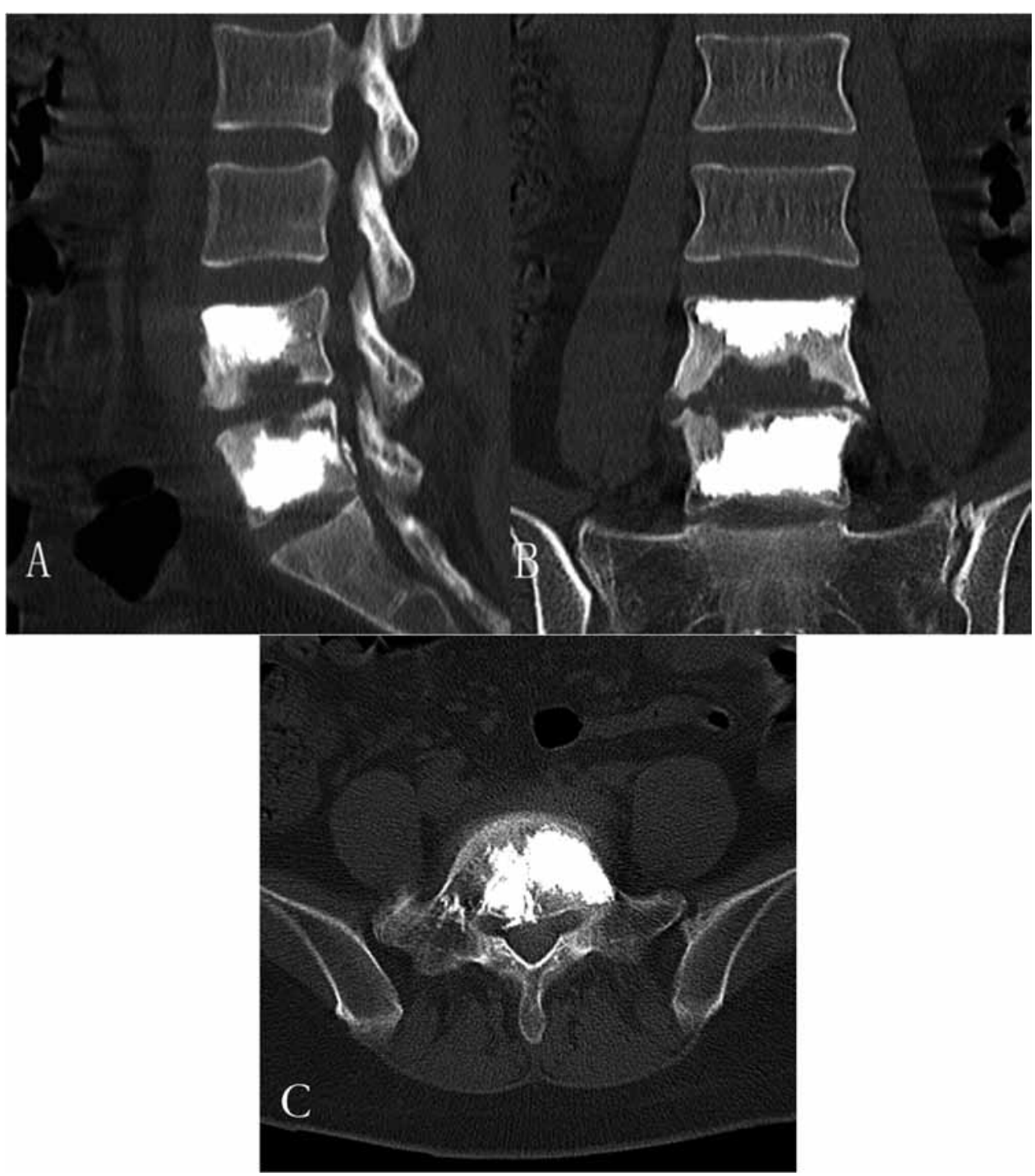

Fig. 3. Sagittal (A) and coronal (B) postprocedural CT images demonstrate PMMA filling the superior L4 vertebral body and the majority of the transitional L5 vertebral body without extravasation into the Schmorl's nodes, or disc space. There is a small amount of cement extravasation into the spinal canal (ligamenta longitudinale posterius) at L5. Axial (C) CT image through this area shows that there is no significant impingement on the thecal sac or nerve roots.

\section{Conclusions}

In conclusion, our study demonstrated that patients suffering from symptomatic SNs, who were not relieved by conservative therapy (analgesics, bed rest, and bracing) may benefit from PVP. There were no complications and the improvement in patient pain continued throughout the long-term follow-up. Future prospective studies are needed to further assess the effectiveness of PVP in the treatment of symptomatic SNs. 


\section{References}

1. Schmorl G. Uber die an den wirbelbandscheiben vork-ommenden ausdehnungs-und zerreisungsvorgange und die dad- urch an ihnen und der wirbelspongiosa hervorgerufenen veranderungen. Verh Dtsch Path Ges 1927; 22:250.

2. Schmorl G, Junghanns $H$. The Human Spine in Health and Disease. 2nd ed. Grune and Stratton, New York, 1971.

3. Hilton RC, Ball J, Benn RT. Vertebral end-plate lesions (Schmorl's nodes) in the dorsolumbar spine. Ann Rheum Dis 1976; 35:127-132.

4. Pfirmann CW, Resnick D. Schmorl nodes of the thoracic and lumbar spine: Radiographic-pathologic study of prevalence, characterization, and correlation with degenerative changes of 1,650 spinal levels in 100 cadavers. Radiology 2001; 219:368-374.

5. Kyere KA, Than KD, Wang AC, Rahman SU, Valdivia-Valdivia JM, La Marca F, Park P. Schmorl's nodes. Eur Spine ] 2012; 21:2115-2121.

6. Takahashi K, Miyazaki T, Ohnari H, Takino T, Tomita K. Schmorl's nodes and low-back pain. Analysis of magnetic resonance imaging findings in symptomatic and asymptomatic individuals. Eur Spine J 1995; 4':56-59.

7. Masala S, Pipitone V, Tomassini $M$, Massari F, Romagnoli A, Simonetti G. Percutaneous vertebroplasty in painful Schmorl nodes. Cardiovasc Intervent $\mathrm{Ra}$ diol 2006; 29:97-101.

8. Wenger M, Markwalder TM. Fluoronavigation-assisted, lumbar vertebroplasty for a painful Schmorl node. J Clin Neurosci 2009; 16:1250-1251.

9. McFadden KD, Taylor JR. End-plate lesions of the lumbar spine. Spine (Phila $\mathrm{Pa} \mathrm{1976)} \mathrm{1989;} \mathrm{14:867-869.}$
10. Kawaguchi $\mathrm{Y}$, Osada R, Kanamori $\mathrm{M}$, Ishihara $\mathrm{H}$, Ohmori K, Matsui H, Kimura T. Association between an aggrecan gene polymorphism and lumbar disc degeneration. Spine (Phila Pa 1976) 1999; 24:2456-2460.

11. Takatalo J, Karppinen J, Niinimäki J, Taimela S, Mutanen P, Sequeiros RB, Näyhä $S$, Järvelin MR, Kyllönen $E$, Tervonen $\mathrm{O}$. Association of modic changes, Schmorl's nodes, spondylolytic defects, high-intensity zone lesions, disc herniations, and radial tears with low back symptom severity among young Finnish adults. Spine 2012; 37:1231-1239.

12. Coulier B, Ghosez JP. Lumbar radiculopathy caused by a tunneling transvertebral Schmorl's node. Skeletal Radiol 2002; 31:484-487.

13. Hansson TH, Keller TS, Spengler DM. Mechanical behavior of the human lumbar spine. II. Fatigue strength during dynamic compressive loading. J Orthop Res 1987; 5:479-487.

14. Bobechko WP, Hirsch C. Auto-immune response to nucleus pulposus in the rabbit. J Bone Joint Surg Br 1965; 47:574-580.

15. Hamanishi C, Kawabata T, Yosii T, Tanaka S. Schmorl's nodes on magnetic resonance imaging. Their incidence and clinical relevance. Spine (Phila Pa 1976) 1994; 19:450-453.

16. Williams FM, Manek NJ, Sambrook PN, Spector TD, Macgregor AJ. Schmorl's nodes: Common, highly heritable, and related to lumbar disc disease. Arthritis Rheum 2007; 57:855-860.

17. Klazen CA, Lohle PN, de Vries J, Jansen $\mathrm{FH}$, Tielbeek AV, Blonk MC, Venmans A, van Rooij WJ, Schoemaker MC, Juttmann JR, Lo TH, Verhaar HJ, van der Graaf $Y$, van Everdingen KJ, Muller AF,
Elgersma OE, Halkema DR, Fransen $\mathrm{H}$, Janssens X, Buskens E, Mali WP. Vertebroplasty versus conservative treatment in acute osteoporotic vertebral compression fractures (Vertos II): An openlabel randomised trial. Lancet 2010; 376:1085-1092.

18. Blasco J, Martinez-Ferrer A, Macho J, San Roman L, Pomés J, Carrasco J, Monegal A, Guañabens N, Peris P. Effect of vertebroplasty on pain relief, quality of life, and the incidence of new vertebral fractures: A 12-month randomized follow-up, controlled trial. J Bone Miner Res 2012; 27:1159-1166.

19. Wagner AL, Murtagh FR, Arrington JA, Stallworth D. Relationship of Schmorl's nodes to vertebral body endplate fractures and acute endplate disk extrusions. AJNR 2000; 21:276-281.

20. Peng B, Chen J, Kuang Z, Li D, Pang X, Zhang $X$. Diagnosis and surgical treatment of back pain originating from endplate. Eur Spine ] 2009; 18:1035-1040.

21. Mattei TA, Rehman AA. Schmorl's nodes: Current pathophysiological, diagnostic, and therapeutic paradigms. Neurosurg Rev 2014; 37:39-46.

22. Jang JS, Kwon HK, Lee JJ, Hwang SM, Lim SY. Rami communicans nerve block for the treatment of symptomatic Schmorl's nodes-a case report. Korean ] Pain 2010; 23:262-265.

23. Olmarker K, Rydevik B. Selective inhibition of tumor necrosis factor-alpha prevents nucleus pulposus-induced thrombus formation, intraneural edema, and reduction of nerve conduction velocity: Possible implications for future pharmacologic treatment strategies of sciatica. Spine (Phila Pa 1976) 2001; 26:863-869. 
